\title{
Analysis of Ukrainian trends of use of Internet technologies in process of marketing interaction with clients of the enterprise
}

\author{
${ }^{1}$ I. O. Ugolkov, ${ }^{2}$ M. F. Honchar, ${ }^{3}$ O. S. Skybinskyi \\ ${ }^{1}$ Lviv Polytechnic National University, Lviv, Ukraine \\ *Corresponding author. E-mail: ievgenii.ugolkov@gmail.com \\ ${ }^{2}$ Lviv Polytechnic National University, Lviv, Ukraine \\ *Corresponding author. E-mail: mykhailo.f.honchar@lpnu.ua \\ ${ }^{3}$ Lviv Polytechnic National University, Lviv, Ukraine \\ *Corresponding author. E-mail: oleksandr.s.skybinskyi@lpnu.ua
}

Paper received 08.02.19; Accepted for publication 13.02.19.

\section{https://doi.org/10.31174/SEND-HS2019-192VII32-04}

\begin{abstract}
The article is aimed at studying the experience of using various communication tools with the clients of the enterprise by Ukrainian commercial enterprises engaged in the sale of pumping equipment and water filters. The purpose of this study is to analyze the domestic experience of interaction of enterprises with their clients and to identify the main trends of such interaction in the context of Internet marketing tools. The following methods were used for the study: analysis, synthesis, grouping, comparison, generalization, graphic and statistical methods. The patterns were found and the effectiveness of each of the analyzed Internet marketing tools was investigated.
\end{abstract}

Keywords: marketing interaction with clients, web marketing tools, SEO, PPC, communications.

Introduction. The development of modern information systems actively changes the interaction between their participants, creates new tools for communication, information transfer and sales. Such changes especially affected the marketing interaction of the enterprise with the client. Marketing interaction refers to all contacts with a client directly or indirectly undertaken by a company in order to influence the adoption of a positive purchasing decision. The notion "marketing interaction" should be understood as a set of direct or indirect contacts with the client realized by the company in order to influence the adoption of a positive purchase decision.

Analysis of recent researches and publications. The following Ukrainian scientists engaged in research on marketing study of the interaction of company with its client using Internet technology: A. Balabanits, A. Yurchak, S. Ilyashenko and others. In addition, a number of international companies such as eMarketer, McKinsey, Google, Walker and others were studying this issue. Considering the two priority customer interaction tools search engine optimization (SEO) and pay-per-click advertising (PPC advertising) that are most often used in Internet marketing, the following statistics for the last few years attract our attention.

The eMarketer [1] study reveals that $89 \%$ of SEO specialists were satisfied with the results of their activities to improve the visibility of the Internet resource in search, traffic and generation of leads in 2015. More than 7 of the 10 surveyed by Marketing Charts [2] have indicated that they feel the improving effectiveness of their SEO promotion. According to eMarketer [3] data, in the small business segment, only $10 \%$ of all enterprises update their information on their own Internet resource once a week, $33 \%$ - once a month, $21 \%$ - once a year or less often.

Speaking about information on an example of mobile versions of the Internet resource, $52 \%$ of users have determined that the most important is the physical address of the organization, $47 \%$ of respondents want to see a map with a location, $44 \%$ consider it necessary to specify hours of work and only $37 \%$ need a telephone number [4]. This points to the importance of serving content that is relevant to the needs of the customers for effective organic search promotion.

It is advisable to consider performance statistics of the second online marketing tool - paid-PPC advertising (Pay-Per-Click). PPC advertising allows you to show ads to the customers who need it, at a time when it is most effective on the platform or on the internet resource they are in. In addition, paid search advertising, as an element of paid advertising, allows you to display ads over organic search engine optimization (SEO). According to Google [5], companies earn about $\$ 2$ from $\$ 1$ spent on AdWords advertising. On average, $41 \%$ of clicks on the Google Network are attributed to the first 3 paid search ads. For some industries, this figure can reach $65 \%$ of clicks. The average number of clicks for a paid ad in the first position is $7.94 \%$. According to Unbounce's data [6], customers who have switched to PPC advertisements are 50\% more likely to buy goods than customers who have gone through an organic search. Search advertising campaigns can increase brand awareness by more then $80 \%$. Google [7] also points out that $75 \%$ of users who find local information prefer to visit the store. Paid advertising can increase the traffic of Internet resources by $300 \%$.

These data look like credible because we receive them from authoritative and verified foreign publications. However, our article is intended to test whether these trends are relevant to domestic enterprises and what characteristics are inherent to our advancement through these Internet marketing tools.

Setting objectives. The purpose of this study is to analyze the Ukrainian experience of engagement of enterprises with their clients through the use of Internet marketing tools such as SEO and PPC and highlight the main trends of such interaction. In order to achieve this goal, general scientific and special methods of scientific research were used in the article, namely: analysis, synthesis, grouping, comparison, generalization and graphic method.

Results. To reveal the tendencies in using various tools of interaction with the client on the Internet resource, an analysis of the activities of Internet resources involved in 
the sale of pumping equipment in Ukraine was conducted. The data was collected as of October 2018. When creating the list, the companies that appeared in Google organic and paid ads on searches for water pumps (keywords in Ukrainian and Russian) were taken into consideration. For analysis, we used data from the analytical services semrush.com and serpstat.com. Data are summarized in Table 1.

For analysis, it is worthwhile to characterize the values of indicators and, if possible, translate them into a mathematical form. Since many of the analyzed online stores deal not only with pumps but also with other products, it significantly affects their Internet marketing strategy. Scores from table 2 were placed on the basis of expert estimates of the width of the product range of each individual Internet resource. The third-party product range is the number of third-party product lines (water filters, related equipment, etc.) that are not related to the trade in pumping equipment.

This indicator can be expressed in points. The highest score ( 5 points) means the widest product range, the lowest score (1 point) means that the website is focused only on the implementation of pumps for water. The visibility indicator of SEO was obtained from the analytical service serpstat.com and shows the overall visibility of the online resource in points in the Google search engine in Ukraine (gooogle.com.ua). Data on total traffic was obtained from the analytical service serpstat.com and shows the average monthly traffic of Internet resources in Google's search engine in Ukraine (gooogle.com.ua). The same number of search queries is the number of clicks that were made on Google's searches in Ukraine (gooogle.com.ua) for a specific website.

Table 1. Analysis of the main indicators of the effectiveness of websites on the example of trading companies of water pumps

\begin{tabular}{|c|c|c|c|c|c|c|c|c|c|c|}
\hline Website & $\begin{array}{c}\text { Third- } \\
\text { party } \\
\text { product } \\
\text { range }\end{array}$ & $\begin{array}{c}\text { SEO } \\
\text { visibility, } \\
\text { scores }\end{array}$ & $\begin{array}{c}\text { Total } \\
\text { traffic, } \\
\text { users }\end{array}$ & $\begin{array}{c}\text { Search } \\
\text { queries, } \\
\text { pcs }\end{array}$ & $\begin{array}{c}\text { PPC } \\
\text { advertising }\end{array}$ & $\begin{array}{c}\text { Facebook } \\
\text { followers, } \\
\text { users }\end{array}$ & $\begin{array}{c}\text { Regular } \\
\text { visitors, } \\
\text { \% }\end{array}$ & $\begin{array}{c}\text { Pages } \\
\text { per } \\
\text { visit, } \\
\text { pcs. }\end{array}$ & $\begin{array}{c}\text { Session } \\
\text { duration, } \\
\text { min }\end{array}$ & $\begin{array}{c}\text { Bounce } \\
\text { rate, } \%\end{array}$ \\
\hline 220volt.com.ua & Very wide & 25,88 & 199533 & 20185 & Presence & 1133 & 31,94 & 6,8 & $11: 04$ & 51,63 \\
\hline storgom.ua & Very wide & 31,14 & 252542 & 32925 & Presence & 176 & 41,75 & 3,27 & $4: 20$ & 46,41 \\
\hline vodyanoy.com.ua & Wide & 8,31 & 65809 & 10473 & Absence & 212 & 30,68 & 3,99 & $3: 51$ & 47,96 \\
\hline voltar.com.ua & Wide & 6,77 & 60909 & 15718 & Presence & 165 & 37,95 & 3,84 & $4: 21$ & 49,87 \\
\hline aquavin.com.ua & Wide & 2,09 & 15333 & 2592 & Absence & 74 & 20,39 & 2,63 & $3: 57$ & 49,22 \\
\hline kty.com.ua & Wide & 1,16 & 9902 & 4481 & Presence & 49 & 42,24 & 8,6 & $21: 01$ & 28,92 \\
\hline hydrostock.com.ua & Average & 1,83 & 14947 & 2993 & Absence & Absence & 25,93 & 2,38 & $2: 50$ & 57,5 \\
\hline akvalend.ua & Average & 0,63 & 5636 & 3149 & Absence & 216 & 62,96 & 2,31 & $3: 25$ & 64,71 \\
\hline nasos-m.com.ua & Average & 1,89 & 18448 & 2422 & Presence & Absence & 23,19 & 2,74 & $3: 44$ & 61,8 \\
\hline snk-lviv.com.ua & Average & 0,38 & 2634 & 371 & Absence & 136 & 28,57 & 4,72 & $5: 47$ & 38,89 \\
\hline vodogin.com.ua & Average & 0,08 & 708 & 394 & Absence & Absence & 7,69 & 1,7 & $0: 46$ & 70 \\
\hline euroaqua.com.ua & Average & 0,03 & 262 & 89 & Absence & Absence & 50,13 & 7,73 & $13: 53$ & 27,27 \\
\hline aquaexpert.com.ua & Average & 0,11 & 935 & 222 & Absence & Absence & 35,29 & 2,2 & $3: 48$ & 50 \\
\hline filter-ua.com.ua & Average & 1,68 & 16503 & 4511 & Absence & Absence & 27,4 & 2,14 & $1: 21$ & 61,9 \\
\hline pedrollo.com.ua & Narrow & 0,47 & 3375 & 278 & Absence & Absence & 52,17 & 4,59 & $2: 40$ & 55,74 \\
\hline wilo.ua & Narrow & 0,96 & 9164 & 1272 & Absence & 1934 & 43,14 & 3,91 & $5: 17$ & 38,81 \\
\hline
\end{tabular}

Table 2. Transfer of performance data of websites into a numerical form for further analysis

\begin{tabular}{|c|c|c|c|c|c|c|c|c|c|}
\hline Website & $\begin{array}{c}\text { Third- } \\
\text { party } \\
\text { product } \\
\text { range }\end{array}$ & $\begin{array}{c}\text { SEO } \\
\text { visibility, } \\
\text { scores }\end{array}$ & $\begin{array}{c}\text { Total } \\
\text { traffic, } \\
\text { users }\end{array}$ & $\begin{array}{c}\text { Search } \\
\text { queries, } \\
\text { pcs }\end{array}$ & $\begin{array}{c}\text { PPC } \\
\text { advertising }\end{array}$ & $\begin{array}{c}\text { Regular } \\
\text { visitors, \% }\end{array}$ & $\begin{array}{c}\text { Pages per } \\
\text { visit, pcs. }\end{array}$ & $\begin{array}{c}\text { Session } \\
\text { duration, } \\
\text { min }\end{array}$ & $\begin{array}{c}\text { Bounce } \\
\text { rate, \% }\end{array}$ \\
\hline 220volt.com.ua & 5 & 25,88 & 199533 & 20185 & 1 & 6,8 & $11: 04$ & 51,63 & 51,63 \\
\hline storgom.ua & 5 & 31,14 & 252542 & 32925 & 1 & 3,27 & $4: 20$ & 46,41 & 46,41 \\
\hline vodyanoy.com.ua & 4 & 8,31 & 65809 & 10473 & 0 & 3,99 & $3: 51$ & 47,96 & 47,96 \\
\hline voltar.com.ua & 4 & 6,77 & 60909 & 15718 & 1 & 3,84 & $4: 21$ & 49,87 & 49,87 \\
\hline aquavin.com.ua & 4 & 2,09 & 15333 & 2592 & 0 & 2,63 & $3: 57$ & 49,22 & 49,22 \\
\hline kty.com.ua & 4 & 1,16 & 9902 & 4481 & 1 & 8,6 & $21: 01$ & 28,92 & 28,92 \\
\hline hydrostock.com.ua & 3 & 1,83 & 14947 & 2993 & 0 & 2,38 & $2: 50$ & 57,5 & 57,5 \\
\hline akvalend.ua & 3 & 0,63 & 5636 & 3149 & 0 & 2,31 & $3: 25$ & 64,71 & 64,71 \\
\hline nasos-m.com.ua & 2 & 1,89 & 18448 & 2422 & 1 & 2,74 & $3: 44$ & 61,8 & 61,8 \\
\hline snk-lviv.com.ua & 2 & 0,38 & 2634 & 371 & 0 & 4,72 & $5: 47$ & 38,89 & 38,89 \\
\hline vodogin.com.ua & 2 & 0,08 & 708 & 394 & 0 & 1,7 & $0: 46$ & 70 & 70 \\
\hline euroaqua.com.ua & 2 & 0,03 & 262 & 89 & 0 & 7,73 & $13: 53$ & 27,27 & 27,27 \\
\hline aquaexpert.com.ua & 2 & 0,11 & 935 & 222 & 0 & 2,2 & $3: 48$ & 50 & 50 \\
\hline filter-ua.com.ua & 2 & 1,68 & 16503 & 4511 & 0 & 2,14 & $1: 21$ & 61,9 & 61,9 \\
\hline pedrollo.com.ua & 1 & 0,47 & 3375 & 278 & 0 & 4,59 & $2: 40$ & 55,74 & 55,74 \\
\hline wilo.ua & 1 & 0,96 & 9164 & 1272 & 0 & 3,91 & $5: 17$ & 38,81 & 38,81 \\
\hline
\end{tabular}

An analysis of the use of PPC advertising was expressed in text and could be translated into " 1 " and " 0 ", where "1" means the presence of PPC advertising on Google, and "0" - its absence. The number of Facebook subscribers can take the value "0" if the Internet resource does not own the page in the given social network. The number of Facebook subscribers did not show a clear relationship with other indicators, which means its low 
impact on such indicators as Website traffic, the number of pages viewed, and so on. This means that this indicator and the tool as a whole does not play a key role in the interaction between enterprises and such type of clients.

Since the analyzed website have a significantly different number of users, for the analysis the regular visitors rate was chosen, which is measured as a percentage of the total number of users of the website. The number of pages per session is the average number of pages viewed by all users per visit on website. Under the session duration we understand the interval from the moment of entry to the moment of the exit from the website. The duration of a session is the average time spent by users on the website in minutes and seconds. Bounce Rate is an indicator that shows the percentage of users who logged out from the website immediately after the first sign-in page. All above values was transformed into the mathematical expression and shown in table 2 .
The results of the Pearson correlation analysis are presented in Table 3. A clear correlation was found between the range and SEO visibility, assortment and number of searches, assortment and traffic. Obviously, the visibility, the number of searches and traffic have almost complete interdependencies. However, these links also show us that the number of product assortments provokes a significant increase in the number of pages of the Internet resource (ie content), as well as improving the performance of SEO. Obviously, the overall visibility of an online resource affects the visibility of specific product categories by keywords in the search engine. That is, expanding the product range or increasing the content on the website in other ways (writing articles in the blog, detailing the existing product range, publishing reviews, etc.) effectively increases the impressions of pages in the search engine, as already discussed in the analysis of research data from other authors.

Table 3. Correlation between performance indicators of websites

\begin{tabular}{|c|c|c|c|c|c|c|c|c|c|}
\hline $\begin{array}{c}\text { Pearson correla- } \\
\text { tion }\end{array}$ & $\begin{array}{c}\text { Third-party } \\
\text { product } \\
\text { range }\end{array}$ & $\begin{array}{c}\text { SEO } \\
\text { visibility }\end{array}$ & $\begin{array}{c}\text { Total } \\
\text { traffic }\end{array}$ & $\begin{array}{c}\text { Search } \\
\text { queries }\end{array}$ & $\begin{array}{c}\text { PPC } \\
\text { advertising }\end{array}$ & $\begin{array}{c}\text { Regular } \\
\text { visitors }\end{array}$ & $\begin{array}{c}\text { Pages } \\
\text { per visit }\end{array}$ & $\begin{array}{c}\text { Session } \\
\text { duration }\end{array}$ & $\begin{array}{c}\text { Bounce } \\
\text { rate }\end{array}$ \\
\hline $\begin{array}{c}\text { Third-party } \\
\text { product range }\end{array}$ & 1 & 0,732 & 0,730 & 0,780 & 0,598 & $-0,053$ & 0,217 & 0,293 & $-0,112$ \\
\hline SEO visibility & 0,732 & 1 & 0,999 & 0,952 & 0,602 & 0,033 & 0,149 & 0,083 & $-0,037$ \\
\hline Total traffic & 0,730 & 0,999 & 1 & 0,961 & 0,613 & 0,036 & 0,137 & 0,073 & $-0,034$ \\
\hline Search queries & 0,780 & 0,952 & 0,961 & 1 & 0,663 & 0,079 & 0,096 & 0,052 & $-0,041$ \\
\hline PPC advertising & 0,598 & 0,602 & 0,613 & 0,663 & 1 & 0,017 & 0,360 & 0,417 & $-0,133$ \\
\hline Regular visitors & $-0,053$ & 0,033 & 0,036 & 0,079 & 0,017 & 1 & 0,374 & 0,312 & $-0,346$ \\
\hline Pages per visit & 0,217 & 0,149 & 0,137 & 0,096 & 0,360 & 0,374 & 1 & 0,923 & $-0,781$ \\
\hline Session duration & 0,293 & 0,083 & 0,073 & 0,052 & 0,417 & 0,312 & 0,923 & 1 & $-0,764$ \\
\hline Bounce rate & $-0,112$ &,- 0037 & $-0,034$ & $-0,041$ & $-0,133$ & $-0,346$ & $-0,781$ & $-0,764 *$ & 1 \\
\hline
\end{tabular}

The second most important trend is that websites with a wider range of products are more likely to use PPC advertising. This may be due to two main reasons: 1) their SEO visibility in specific product categories reaches the first position and they maximize the effect of implementing an advertising campaign in paid advertisements over an organic search; 2) websites that have a greater organic visibility have Internet marketers in their state who are engaged in their promotion while smaller websites do not have these specialists or replace them with specialists in related professions. The confirmation of the first statement suggests that a correlation was found between the visibility of websites, traffic, the number of searches and the use of PPC advertising. That is, websites that are more promoted by SEO use PPC advertising more often. Since this is a twoway communication, the opposite can be taken - those Internet resources that use PPC advertising are better promoted by SEO. In fact, the visibility of an online resource in search advertising and paid advertisements simultaneously maximizes the likelihood of being spotted by customers in the search, which is why these two tools are often used in a complex.

As for updating the content on the website, there are also interesting statistics. There is a weak reverse correlation between the share of regular visitors on the website and the bounce rate. It's obvious that regular visitors rarely go out of the first page, trying to get more information from the visit. That is why the constant updating of the actual content of the website is so necessary. In addition, there is a strong reverse correlation between session duration and bounce rate (first page exits). On the one hand, all services that provide statistics of websites calculate the duration of a session only if you switch to the second page. On the other hand, these statistics clearly indicate the need for multi-level and interconnected content, which would be easily perceived by the user and directed him to solve a specific problem. It is also worth noting the weak correlation between the duration of the session and the product range. It shows us that websites that have more pages with content keeps better client online.

Conclusions. In modern conditions, with the help of the latest tools, marketers can track the interaction of potential clients with the brand to better understand the impact of each interaction on the purchase decision. That is why the domestic experience of cooperation of enterprises with its clients with the help of websites was investigated. It has been found that clients attracted by PPC advertising have better purchasing performance than other website visitors, meaning we can see a moderate correlation between the presence of PPC ads and indicators such as session duration and the number of pages per session. Consequently, users who go for paid search advertising are more motivated and are often looking for more information to resolve their own 
problem on the Internet. In addition, the statistics clearly indicate the need for multi-level and interrelated content, which would be easily perceived by the user and directed him to solve a specific problem.

\section{REFERENCES}

1. For Effective SEO, Content Is King. eMarketer. (2015). 5. Coe, <https://www.emarketer.com/Article/Effective-SEO-ContentKing/1012639>. (2019, February, 07)

2. Most Effective - and Difficult - SEO Tactics. Marketing charts. (2015). <https://www.marketingcharts.com/digital55896>. (2019, February, 05)

3. SMBs Get More Mobile. One in three have a mobile-

optimized website. eMarketer. (2015). <https://www.emarketer.com/Article/SMBs-MoreMobile/1013010>. (2019, February, 06)

4. Marchant, R. (2015). 61\% of Mobile Users More Likely to Contact a Local Business with a Mobile Site. BrightLocal. <https://www.brightlocal.com/2015/05/13/61-of-mobileusers-more-likely-to-contact-a-local-business-with-a-mobilesite/>. (2019, February, 06) $<$ https://economicimpact.google.com/introduction/\#/?sections activeEl=introduction>. (2019, February, 04)

6. 1Gardner, O. (2012) SEO vs PPC - Time for a Fight! <https://unbounce.com/ppc/seo-vs-ppc-infographic/>. (2019, February, 06)

7. New Research Shows How Digital Connects Shoppers to Local Stores (2014). <https://www.thinkwithgoogle.com/consumer-insights/howdigital-connects-shoppers-to-local-stores/>. (2019, February, 06) 